\title{
LOAD DISTRIBUTION AND CONTACT OF AXLE BOX BEARINGS IN ELECTRIC MULTIPLE UNITS
}

\author{
Cheng, L. Z. ; Liu, D. K. ${ }^{* * * * * * \# ; ~ W a n g, ~ Y ., ~}{ }^{* * * * *} \&$ Chen, A. Q. ${ }^{* *, * * *}$ \\ State Key Laboratory of Mechanical Behavior and System Safety of Traffic Engineering Structures, \\ Shijiazhuang Tiedao University, 17 East Road, Second North Ring, Shijiazhuang, P. R. China \\ ${ }^{* *}$ Zhejiang Provincial Special Equipment Inspection and Research Institute, 211 Kaixuan Road, \\ Hangzhou, P. R. China \\ *** Key Laboratory of Special Equipment Safety Testing Technology of Zhejiang Province, \\ 211 Kaixuan Road, Hangzhou, P. R. China \\ **** Center for Transportation Infrastructure Systems, The University of Texas at El Paso, \\ 500 West University Avenue, El Paso, Texas, United States \\ E-Mail: 11116336@bjtu.edu.cn ( ${ }^{\#}$ Corresponding author)
}

\begin{abstract}
The rolling bearing, as the key part of the moving component of an electric multiple unit (EMU), its mechanical behaviour has become an active area of research in the development of high-speed EMUs. To provide a reliable basis for evaluating service life span and operational reliability of double-row tapered roller bearings, the load distribution of axle box bearings and the contact stress of bearings were investigated in this study. The methods of numerical analysis and actual load measurement were performed to calculate the internal load distribution. After obtaining the internal roller load distribution relation, a model of a single roller contacting the inner and outer raceways was established to calculate the contact stress state using Abaqus software and the Hertz theory. Results show that the contact load of each roller in the bearing decreases with the increase of the azimuth angle until the roller is outside the load-bearing area. The contact half width and the contact stress distribution of the simulation and the theoretical computation results are consistent. This study can provide a basis for the design and service life evaluation of this type of bearing.

(Received in January 2019, accepted in May 2019. This paper was with the authors 1 month for 2 revisions.)
\end{abstract}

Key Words: Axle Box of EMU, Double-Row Tapered Roller Bearing, Load Distribution, Contact Stress

\section{INTRODUCTION}

With the needs of railway enterprises to adapt to the rapid development of the national economy, railway transportation has been revitalized around the world. By the end of 2010, China Railway had put into operation 480 high-speed trains and had achieved the highest speed among railways worldwide with a speed of $486.1 \mathrm{~km}$ per hour. As an important mechanical component in the high-speed electric multiple units (EMU) transmission system, the bearing withstands a high cycle alternating load in a harsh working environment [1], which presents a challenge in the development of transmission systems. Therefore, the reliability test design and evaluation method for bearings are the core issues of research. In addition, rail transit equipment typically requires high reliability under severe conditions. Bearings are core components of equipment systems and often require special development or customization. Therefore, it is necessary to conduct in-depth research on axle box bearings.

The axle box bearings of an EMU operate under the conditions of high speed, high temperature, heavy load, and complicated force. The working environment is harsh, and the failure of the bearings may cause substantial economic losses and even catastrophic disasters. It is difficult and costly to experiment with and test bearings. Finite element simulation (FES) is a cost-effective research method to analyse the load distribution and contact stress state, and it is receiving more and more attention [2]. In the early research stage, researchers could only 
make assumptions about the state of the bearing when it was based on the geometric relation of the bearing and the theory of bearing mechanics analysis. Therefore, the load distribution and motion conditions could only be roughly estimated, so the results could deviate from the actual situations. In recent years, with the development of numerical methods such as finite element and boundary element and the development of large-scale finite element software, it has become possible to study the contact problems between elastic structures and complex structures. The continuous improvement of such software has promoted the development of 3D numerical simulation of rolling bearings [3]. At present, the dynamic analysis of doublerow tapered roller bearings for EMU is rarely studied, and the consideration of the interaction between the load distributions of double-row tapered rollers is also insufficient.

As a key technical component to ensure the quality and safety of train operation, the working conditions and technical requirements of this double-row tapered roller bearing are obviously different from the same type of traditional bearings. The bearing must withstand not only a large radial load but also a certain axial load. And the bearing requires high reliability to avoid any failure [4]. Therefore, there is an urgent need to accurately analyse the load distribution of axle box bearings in the actual operation of EMUs. Based on the measured spring and tumbler load of the EMU axle box, the load distribution of the bearing double-row tapered roller and the contact stresses between the roller and the inner and outer raceways were analysed. The results provided calculation methods and data support for the analysis of strength, life, and reliability of EMU axle box bearings as well as guidance for the design and manufacturing process of EMU axle box bearings.

\section{LITERATURE REVIEW}

In recent years, experts have carried out a great deal of research on bearing load distribution and contact mechanics [5-7]. Houpert [8] established the dynamic numerical simulation model of the tapered roller bearing, and the force of the cage was analysed in depth, including the change of the contact state between the roller and the cage and the calculation of the cage force. However, the model was just a 2D plane model. Wei et al. [9] used programming to calculate the overall load distribution of the tapered roller bearing and obtained the roller position where the maximum load was located. Yan et al. [10] established a 3D model of the bearing based on the pseudo-kinetic analysis method and analysed the load distribution. After obtaining the bearing load distribution, the contact stress distribution of a single roller and the raceway was solved. However, these studies only investigated single-row tapered roller bearings and did not consider the interaction of load distribution between double-row tapered rollers used in the EMU axle box bearings.

Slack and Sadeghi [11] carried out the simulation of bearing display dynamics and analysed the causes of bearing fatigue life. Zamponi et al. [12] performed an explicit dynamic simulation of the occurrence of defects on the surface of the rolling contact and analysed the contact pressure and contact stress of the raceway when the working area was spalling. Yin et al. [13] used ANSYS/LS-DYNA to establish a fault finite element 3D solid model of pointdeficient deep groove ball bearings and showed dynamic analysis of the bearing under normal operation and metal spalling. The equivalent stress cloud map and stress distribution map were analysed, and the vibration characteristics of the two were analysed. A feasible fault diagnosis and verification method was provided. Cui et al. [14] used LS-DYNA software to analyse the dynamics of rolling bearings for railway locomotives. Under the influence of thermal stress, the distribution of bearing contact stress and its time-varying law were obtained. However, these studies all used explicit dynamics for the calculation. Explicit methods are not as good as implicit methods in terms of the accuracy of the results. Wang et al. [15] used the pseudo-kinetic method to establish the dynamic model of any loaded ball 
bearing and proposed an efficient solution to the nonlinear equations in engineering practice. The model was verified by Gupta's dynamic program. The structure of the tapered roller bearing is quite different from the ball bearing, and the contact laws of the two are also different. With the continuous development of numerical simulation technology [16], simulation prediction technology has become an effective means of bearing design in engineering applications.

Due to the highly nonlinear nature of the bearing, it is difficult to find an accurate mechanical model to correctly express and predict the load distribution state of the bearing. Therefore, there is still room for improvement and deep exploration in bearing research. In this paper, the calculation model of a double-row tapered roller bearing of an axle box bearing was established by means of numerical simulation. Based on the measured load data, the internal load distribution and contact stress of the bearing were discussed, and the basis for the design of an axle box bearing structure was provided.

The remainder of this study is organized as follows. Section 2 describes the research progress of bearing load distribution and contact mechanics. Section 3 gives the numerical calculation model of the load distribution and the tapered roller contact stress method. Section 4 shows the internal load distribution and contact stress state of the double-row tapered roller bearing calculated based on the measured bearing load. Conclusions are summarized in Section 5 .

\section{BASIC MODELING CONSIDERATION}

\subsection{Load distribution numerical calculation model}

The double-row conical roller bearing is considered herein with the assumption that the clearance of the bearing is zero. The roller azimuth angle is denoted as $\varphi_{j}$.

When the bearing is subjected to combined loads of radial load $F_{r}$ and axial load $F_{a}$, the radial and axial displacements of the bearing are represented by $\delta_{r}$ and $\delta_{a}$, respectively. Fig. 1 shows the force and displacement of the double-row conical roller bearing. The symbol $\alpha$ denotes the nominal contact angle. The force balance equations are expressed as:

$$
\begin{gathered}
F_{\mathrm{r}}=\sum_{j=0}^{Z-1}\left(Q_{1 \mathrm{r} \varphi j}+Q_{2 \mathrm{r} \varphi j}\right)=\sum_{j=0}^{Z-1}\left(Q_{1 \varphi j}+Q_{2 \varphi j}\right) \cos \varphi_{j} \cos \alpha \\
F_{\mathrm{a}}=\sum_{j=0}^{Z-1}\left(Q_{\mathrm{la} \varphi j}-Q_{2 \mathrm{a} \varphi j}\right)=\sum_{j=0}^{Z-1}\left(Q_{1 \varphi j}-Q_{2 \varphi j}\right) \sin \alpha
\end{gathered}
$$

where $Q_{1 r \varphi j}$ and $Q_{2 r \varphi j}$ are the radial contact loads of column 1 and column 2, respectively, when the azimuth angle is $\varphi_{j} ; Q_{1 a \varphi j}$ and $Q_{2 a \varphi j}$ denote the axial contact loads of column 1 and column 2, respectively, when the azimuth angle is $\varphi_{j}$; and $Q_{1 \varphi j}$ and $Q_{2 \varphi j}$ represent the contact loads of column 1 and column 2, respectively, when the azimuth angle is $\varphi_{j}$.

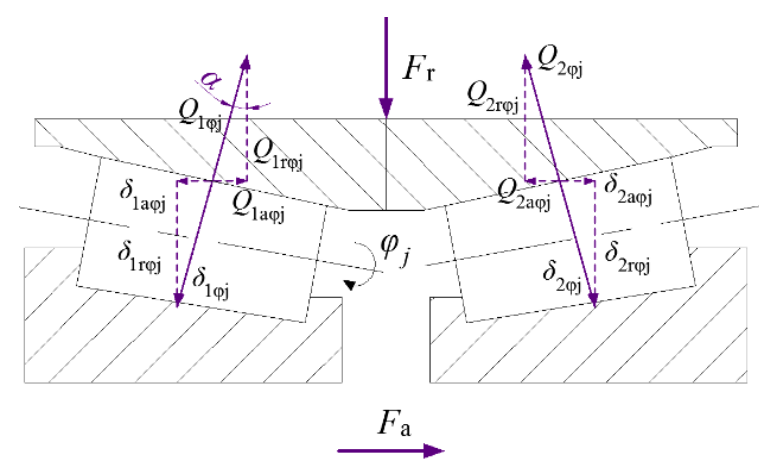

Figure 1: Force and displacement of bearing. 
There are two inner raceways and one outer raceway in a double-row conical roller bearing. we obtain $2 Z+2$ nonlinear equations which need to be solved in order to obtain the load distribution. There are exactly $2 Z+2$ unknowns: $\delta_{1 \varphi j}, \delta_{2 \varphi j}(j=0,1, \ldots, Z-1), \delta_{r}$, and $\delta_{a}$. The radial displacement $\delta_{r}$, axial displacement $\delta_{a}$, and load distribution of the bearing can be obtained by solving the nonlinear equations with the Newton-Raphson iteration method.

\subsection{Tapered roller contact stress}

After the load distribution of the inner tapered roller is solved, the contact load of a single roller can be known, so the contact model can be established for the contact relationship of the single roller and the raceway. In this paper, the contact stress distribution of a tapered roller bearing is approximated by two methods. The first method is calculated based on the Hertz theory, which can be divided into the equivalent cylinder method and the slice method [17]. The second method is FES, in which the tapered roller contact model is established, and the contact stress distribution of the tapered roller bearing is solved by the FES method.

(1) Theoretical calculation of contact stress of tapered roller

a) Equivalent cylinder method

The raceway-contacting form of the cylindrical roller and the tapered roller is a line contact model, and since the angles $\alpha_{i}$ and $\alpha_{o}$ are small, as shown in Fig. 2, the tapered roller can be approximated as an equivalent cylindrical roller. The equivalent roller diameter is the average diameter of the tapered roller, that is, the radius of curvature of the roller is $R=0.5\left(D_{\max }+D_{\min }\right)$. The calculation formulas of the contact half width and the maximum contact stress are listed in Table I; in the table, the contact load is $Q$, the elastic modulus $E_{1}=E_{2}=E=210 \mathrm{GPa}$, and the Poisson's ratio is 0.3 .

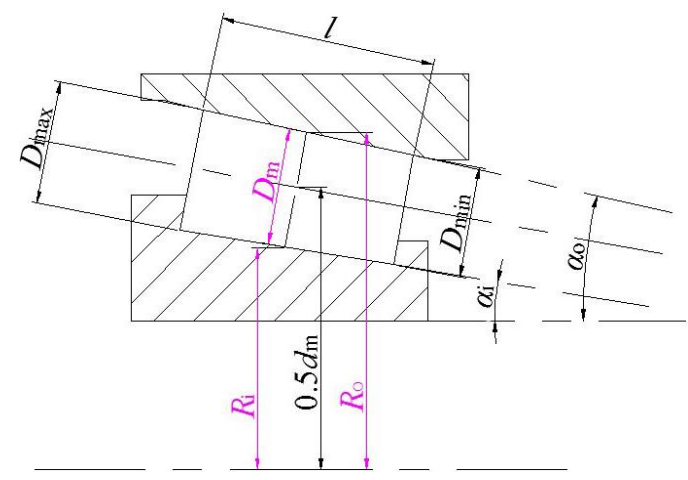

Figure 2: Schematic diagram of tapered roller size.

Table I: Calculation formula for contact half width and maximum contact stress.

\begin{tabular}{|c|c|c|c|}
\hline Contact pair & Contact type & Contact half width $\boldsymbol{b}$ & Maximum contact stress $\sigma_{\max }$ \\
\hline Roller and inner raceway & \multirow{2}{*}{ Roller and outer raceway } & $b_{\mathrm{i}}=1.522 \sqrt{\frac{Q}{l E} \frac{R R_{\mathrm{i}}}{R+R_{\mathrm{i}}}}$ & $\frac{2 Q}{\pi l b_{\mathrm{i}}}$ \\
\hline & & $b_{0}=1.522 \sqrt{\frac{Q}{l E} \frac{R R_{\mathrm{o}}}{R_{\mathrm{o}}-R}}$ & $\frac{2 Q}{\pi l b_{\mathrm{o}}}$ \\
\hline
\end{tabular}

Note: $i$-subscript represents inner raceway; $o$-subscript represents outer raceway.

b) Simplified slice method

The curvature of each point on the contact line between the tapered roller and the inner or outer raceways is not the same, so the equivalent cylinder method cannot describe the 
distribution of the contact stress along the contact line. As shown in Fig. 3, the tapered roller is divided into $m$ small slices $\Delta l=l / m$ along the $y$-axis direction of the contact line. If the slice is sufficiently small, the diameter of the roller inside the slice can be regarded as uniform. Thus, the contact stress in the slice can be calculated by the equivalent cylinder method.

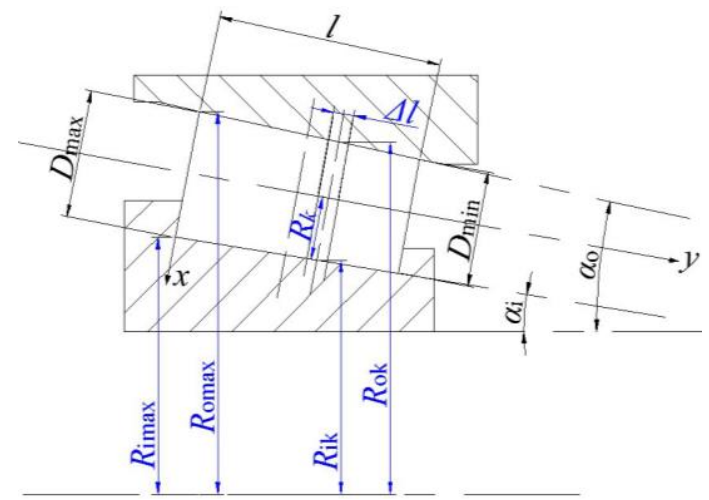

Figure 3: Schematic diagram of the tapered roller slice method.

It is assumed that the contact load $Q$ is uniformly distributed in the direction of the contact line, so the contact load on each slice is $\Delta Q=Q / \mathrm{m}$. It can be seen from Fig. 3 that the diameter of the tapered roller gradually decreases along the positive direction of the $y$-axis, and the radii of curvature of the inner and outer raceways decrease simultaneously in a linear manner. The variation equation can be solved by the least squares method to obtain the radius of the equivalent cylindrical roller and the radii of curvature of the inner and outer raceways in the $k^{\text {th }}$ slice:

where

$$
\begin{gathered}
R_{k}=\frac{D_{\text {min }}-D_{\text {max }}}{2 l} y+\frac{D_{\text {max }}}{2} \\
R_{\mathrm{i} k}=-\sin \left(\alpha_{\mathrm{i}}\right) y+R_{\mathrm{i} \text { max }}, R_{\mathrm{o} k}=-\sin \left(\alpha_{\mathrm{o}}\right) y+R_{\mathrm{o} \text { max }}
\end{gathered}
$$

$$
y=\frac{k l+(k-1) l}{2 m}=\frac{2 k-1}{2} \frac{l}{m}
$$

When the roller is divided, the contact area is also divided, as shown in Fig. 4. Taking the roller and the inner raceway as an example, the contact area between the roller and the inner raceway is divided into $m$ rectangular regions of length $\Delta l$. The contact stress is evenly distributed along the $y$-axis contact line inside the region, the $x$-axis direction conforms to the Hertz contact stress distribution, and the shear stress between the slices is ignored. The half width of the $k^{\text {th }}$ slice contact surface can be written as:

$$
b_{\mathrm{i} k}=1.522 \sqrt{\frac{\Delta Q}{\Delta l E} \frac{R_{\mathrm{i} k} R_{k}}{R_{k}+R_{\mathrm{i} k}}}, b_{\mathrm{o} k}=1.522 \sqrt{\frac{\Delta Q}{\Delta l E} \frac{R_{\mathrm{o} k} R_{k}}{R_{\mathrm{o} k}-R_{k}}}
$$

(2) Tapered roller contact simulation

In the finite element simulation, in order to obtain a relatively accurate stress distribution of the contact area between the roller and the raceway, it is necessary to refine the contact area mesh. Hypermesh software is used to refine the mesh near the contact area. After refinement, the minimum mesh size is within $0.03 \mathrm{~mm}$ to meet the accuracy requirements, and the mesh size in the non-contact area is increased to reduce the calculation scale. The finite element model has a total of 208,930 units and 227,511 nodes, as shown in Fig. 5. 


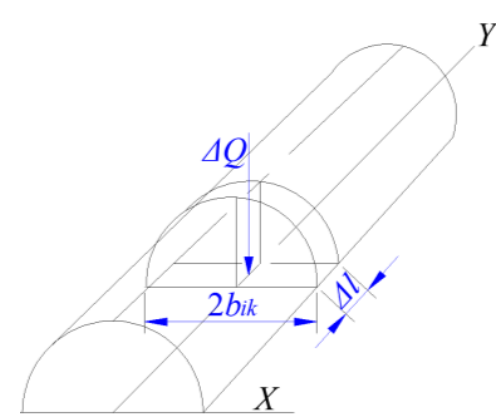

Figure 4: Schematic diagram of the slice method of the tapered roller contact area.

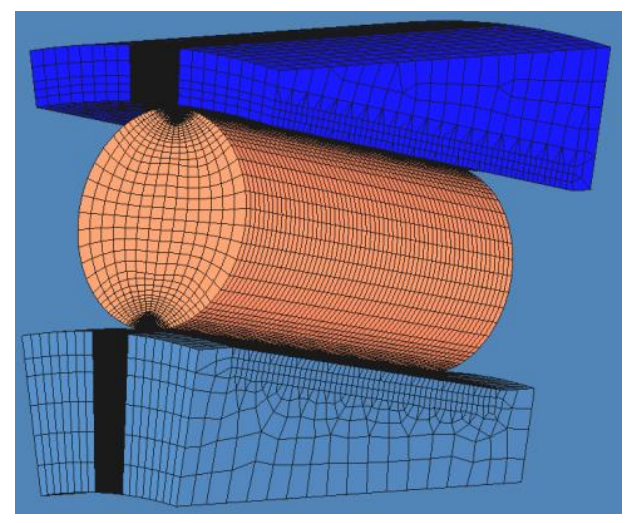

Figure 5: Tapered roller bearing meshing model.

\section{SIMULATION}

\subsection{Tapered roller bearing load distribution}

The key geometric parameters of the tapered roller bearing are the basis for the internal load calculation and contact analysis of the tapered roller. The bearing load distribution is calculated using an axle box bearing of an EMU as an example.

The direction of the axial load of the double-row tapered roller bearing is set to be the first row of rollers and the second row of rollers, and the rollers of each row are numbered to facilitate the drawing of the load distribution. The bearing loading and the roller serial number are shown in Fig. 6.

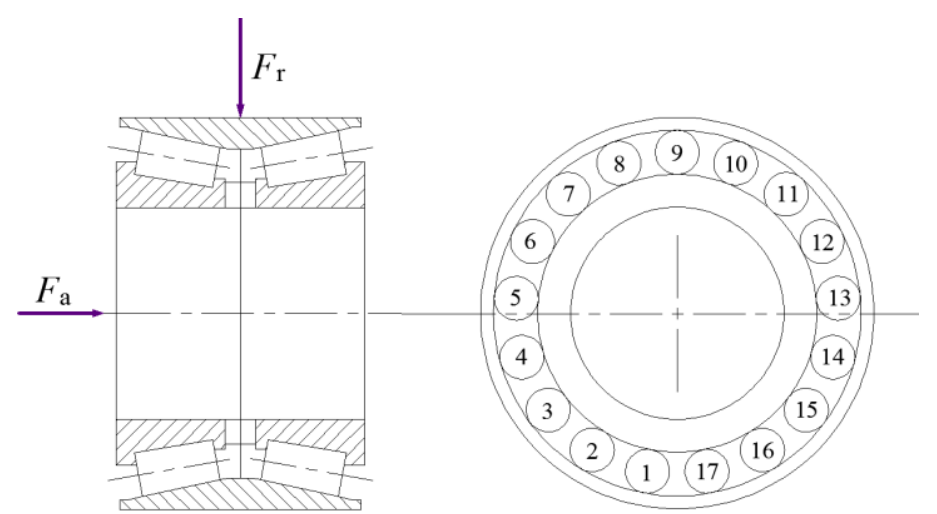

Figure 6: Schematic diagram of double-row tapered roller bearing loading condition and roller numbering.

From the measured axle box spring and tumbler data [18], the axle box bearing is subjected to a maximum radial load of $66 \mathrm{kN}$ and a maximum axial load of $12 \mathrm{kN}$. It is assumed that the radial load and the axial load are simultaneously applied to solve the internal 
load distribution of the double-row tapered roller bearing, and the calculation results are shown in Fig. 7.

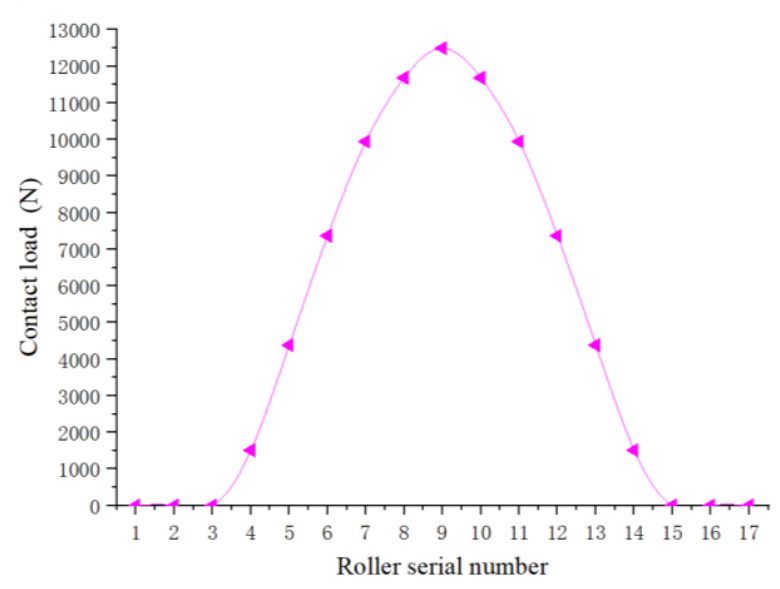

a) the first column of rollers

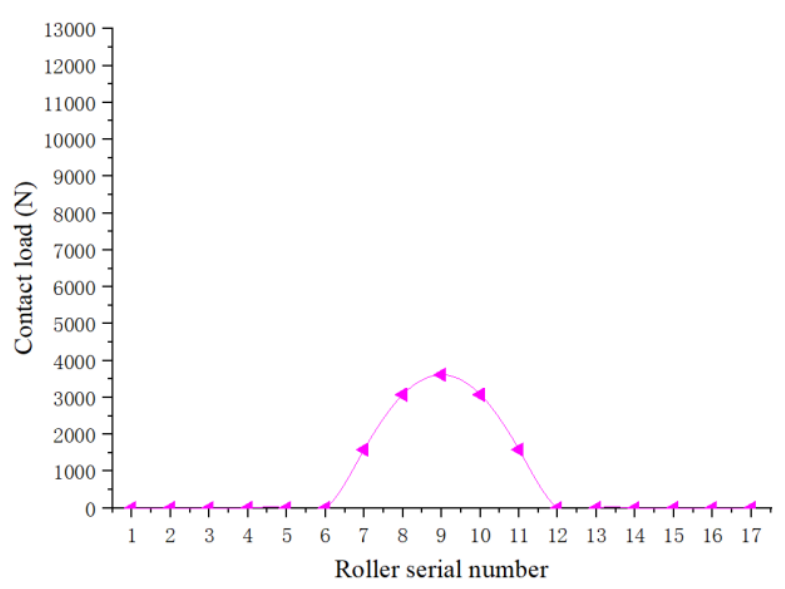

b) the second column of rollers

Figure 7: Load distribution of double-row tapered roller.

It can be seen that the load in the double-row tapered roller bearing decreases with the increase of the azimuth angle until the roller is not subjected to the load, which is outside of the bearing zone. The first row of rollers is subjected to a large contact load, and 11 of the 17 rollers are carried, whereas the second column is subjected to a small contact load, and only five rollers are carried. This is due to the special structure of the double-row tapered roller bearing, which causes the bearing to be subjected to both radial and axial loads. The maximum contact load occurs at the position where the azimuth angle of the first column is $0^{\circ}$ (i.e., roller \#9), and the maximum load is $12.49 \mathrm{kN}$.

\subsection{Tapered roller contact stress}

(1) Analysis of theoretical calculation results

When the axle box bearing simultaneously acts on the maximum radial and axial loads of normal operation, the maximum contact load of the single roller is $12.49 \mathrm{kN}$. The roller with azimuth angle of $0^{\circ}$ is calculated and substituted into the geometrical dimensions and material parameters of the tapered roller bearing. It can be calculated that the contact half width between the roller and the inner raceway is $0.1782 \mathrm{~mm}$, and the maximum contact stress is 892.39 MPa. The half-width between the roller and the outer raceway is $0.2057 \mathrm{~mm}$, and the maximum contact stress is $772.98 \mathrm{MPa}$. Fig. 8 shows the stress distributions of the roller and the inner and outer raceways calculated by the equivalent cylinder method.

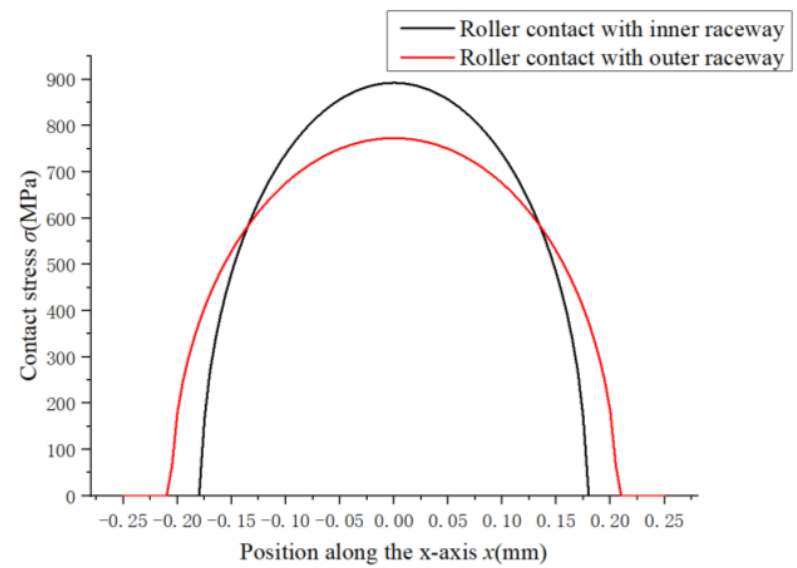

Figure 8: Inner and outer raceway contact stress distributions along the $x$-axis. 
It can be seen from Fig. 8 that the inner raceway is more concentrated than the outer raceway and is more susceptible to damage. The equivalent cylinder method makes many approximations in the solution process, so it can only be used to estimate the contact stress. If it is necessary to conduct a relatively detailed study on the stress distribution in the direction of the contact line, it is necessary to use the slice method.

In order to obtain a sufficiently accurate slice effect, the number of rectangular regions divided by the contact area between the roller and the inner raceway is $m=180$, and the corresponding calculation program is compiled by MATLAB to obtain the contact half width and a maximum of 180 sliced rollers with the inner and outer raceways. The corresponding MATLAB program is also compiled to calculate the contact stress distributions along the $x$ axis direction for the inner and outer raceways of the tapered roller. The stress distribution fields of the inner and outer raceway contact regions can be obtained by combining the $y$-axis stress distribution, as shown in Fig. 9.

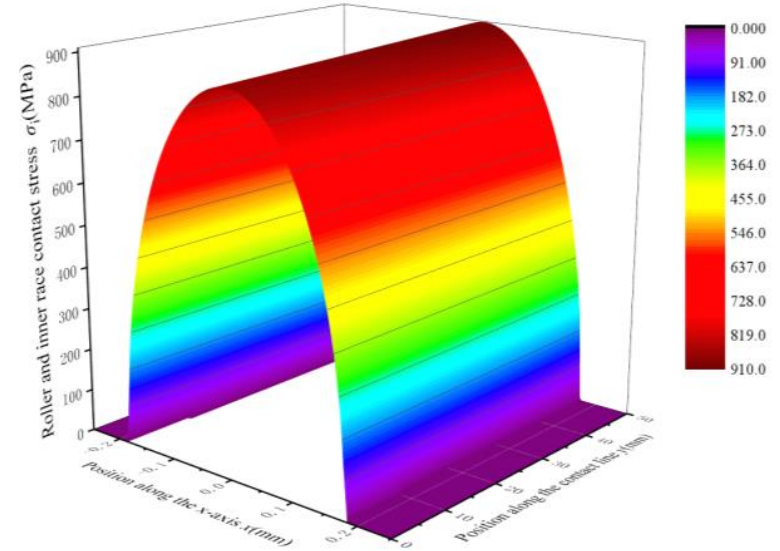

a) Between roller and inner raceway

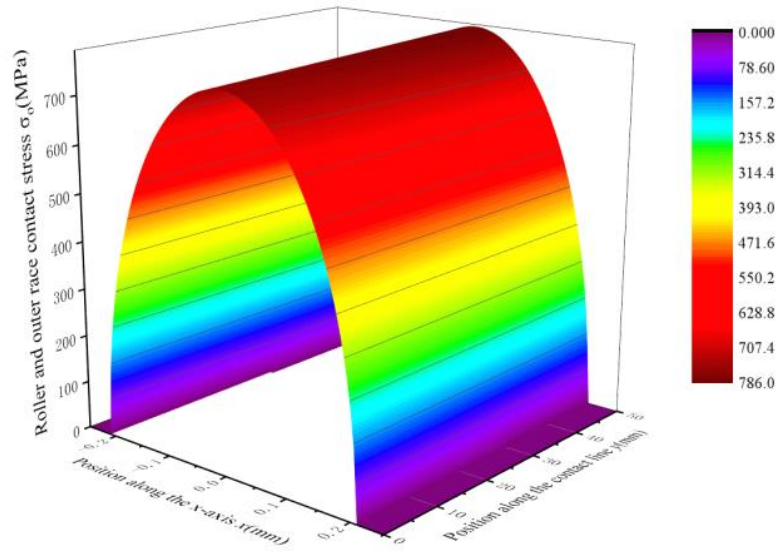

b) Between roller and outer raceway

Figure 9: Stress field in contact area.

It can be seen from Fig. 9 that the contact half widths and the maximum contact stresses for the inner and outer raceways change in the same way along the direction of the contact line, and both vary linearly. Along the $y$-axis of the contact line, that is, the direction from the big end to the small end of the tapered roller, the contact half width values of the inner and outer raceways gradually decrease, and the maximum contact stress values gradually increase. The simplified slice method ignores the tangential load between slices when calculating the contact stress, which simplifies the correlation between the slices. Therefore, this method cannot reasonably explain the phenomenon of stress concentration at the edge of the roller.

(2) Simulation results and comparison with theoretical calculations

Surface stress is applied to the surface of the outer raceway to apply a vertical load of $12.49 \mathrm{kN}$, which is calculated by the static implicit algorithm in Abaqus. It can be seen that the contact relation between the roller and the raceway can be established reliably. There is no serious discontinuous iteration in the calculation process, which verifies the stability of the boundary condition. The inner and outer raceway contact areas are in the form of elongated rectangular zone as shown in Fig. 10.

The simulation results are compared with the Hertz theoretical calculation results in Table II. From the comparison between the simulation and the theoretical calculation results, it can be seen that the simulated half-widths of the inner and outer raceway contact are consistent with the theoretical calculation values, and the relative errors are extremely small. In contrast, the relative errors between the theoretical and simulated contact maximum stress values of the inner and outer raceways are much larger. The errors are related to the contact stress distribution in the $x$-axis direction as well as the grid size and quality. In order to solve the 
problem of contact stress error caused by grid precision, the simulated discrete data are fitted with a semi-elliptic distribution.

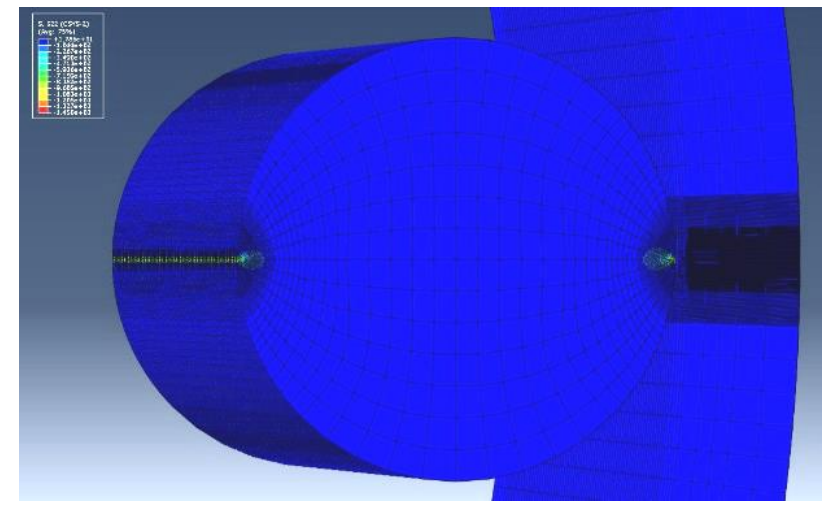

Figure 10: Tapered roller contact normal stress cloud map.

Table II: Comparison of simulation and Hertz theoretical calculation results.

\begin{tabular}{|c|c|c|c|c|c|c|}
\hline \multirow{2}{*}{ Parameter } & \multicolumn{3}{|c|}{ Contact half width $(\mathrm{mm})$} & \multicolumn{3}{c|}{ Contact maximum stress (MPa) } \\
\cline { 2 - 7 } & $\begin{array}{c}\text { Theoretical } \\
\text { value } b_{1}\end{array}$ & $\begin{array}{c}\text { Simulated } \\
\text { value } b_{2}\end{array}$ & $\begin{array}{c}\text { Relative error } \\
\left|b_{2}-b_{1}\right| / b_{1}(\%)\end{array}$ & $\begin{array}{c}\text { Theoretical } \\
\text { value } \sigma_{1}\end{array}$ & $\begin{array}{c}\text { Simulated } \\
\text { value } \sigma_{2}\end{array}$ & $\begin{array}{c}\text { Relative error } \\
\left|\sigma_{2}-\sigma_{1}\right| / \sigma_{1}(\%)\end{array}$ \\
\hline $\begin{array}{c}\text { Inner } \\
\text { raceway }\end{array}$ & 0.1782 & 0.1733 & 2.75 & 892.39 & 1053.01 & 18.00 \\
\hline $\begin{array}{c}\text { Outer } \\
\text { raceway }\end{array}$ & 0.2057 & 0.2014 & 2.09 & 772.98 & 904.87 & 17.06 \\
\hline
\end{tabular}

Fig. 11 shows the simulation, theoretical calculation, and regression results of the distributions of the inner and outer raceway contact stresses in the $x$-axis direction. The $x$-axis direction of the abscissa indicates the half-width direction of the contact, and the ordinate indicates the magnitude of the stress in the contact of the roller with the inner and outer raceways. It can be seen from the figures that the distributions of the contact stress simulation values along the $x$-axis direction are consistent with the theoretical values, and the simulation results have a large error in the maximum contact stress at the intermediate point due to the influence of the grid size accuracy, which is larger than the theoretical value. The regression results of the simulation data are closer to the theoretical calculations.

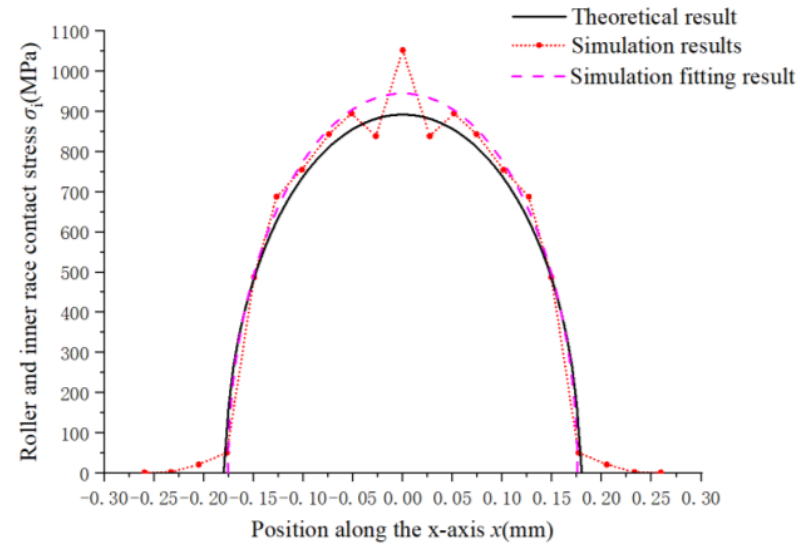

a) Between roller and inner raceway

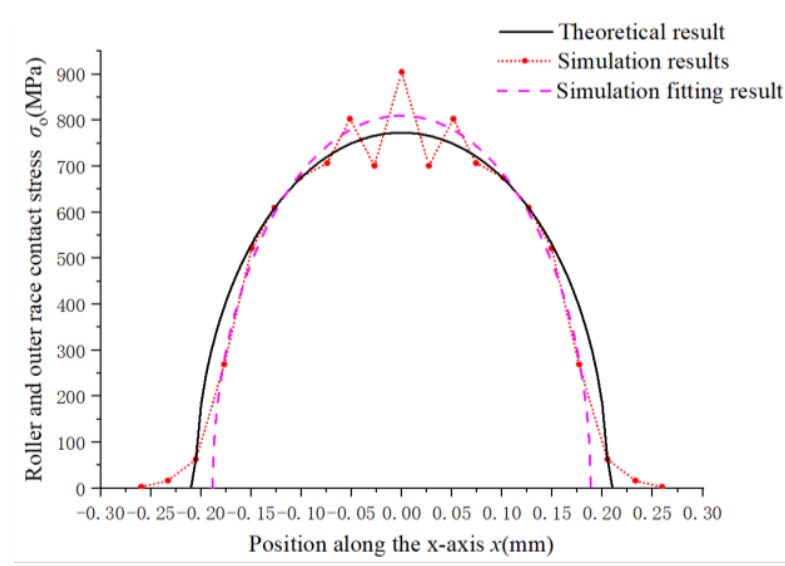

b) Between roller and outer raceway

Figure 11: Contact stress distribution along the $x$-axis.

As shown in the simulation results, the contact stress values of the nodes on the centre line of the inner and outer raceway contact areas from the big end to the small end are obtained, 
and a linear function is fit to the data for each raceway. Additionally, these results are compared with the calculation results of the slice method, as shown in Fig. 12. The simulation results show that the two ends of the roller have the peak of contact stress due to the stress concentration, which is in accordance with the true contact stress state. From the big end to the small end of the tapered roller, the contact stress gradually increases, which is consistent with the conclusion drawn by the slice method. The simulated contact stress values fluctuate along the direction of the contact line, and the fluctuation is caused by the large mesh size. In order to reduce the mesh size error, a linear function is fit to the data. From the fitting results, the contact stress along the contact line is largely consistent with the slope of the theoretical result for both the inner and outer raceways, and its value is slightly larger, indicating that the quality of the contact model is relatively reliable, and the data calculated by the simulation can be used for the analysis.

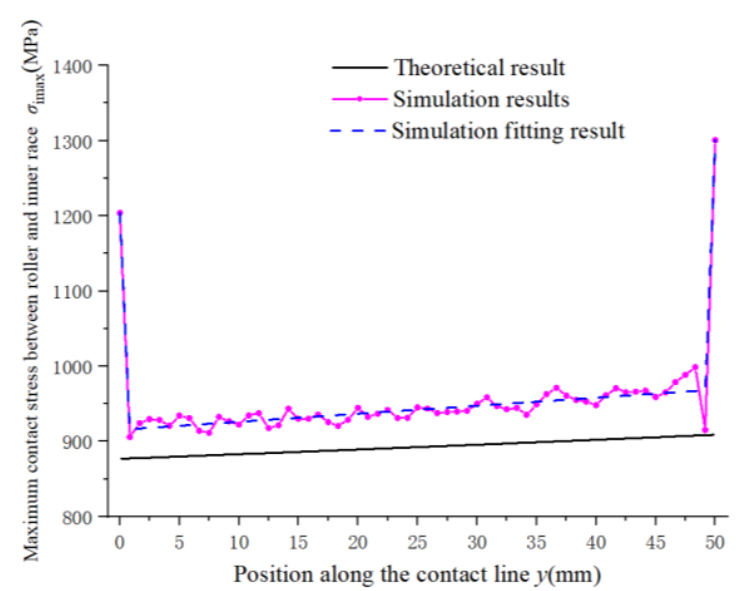

a) Between the roller and the inner raceway

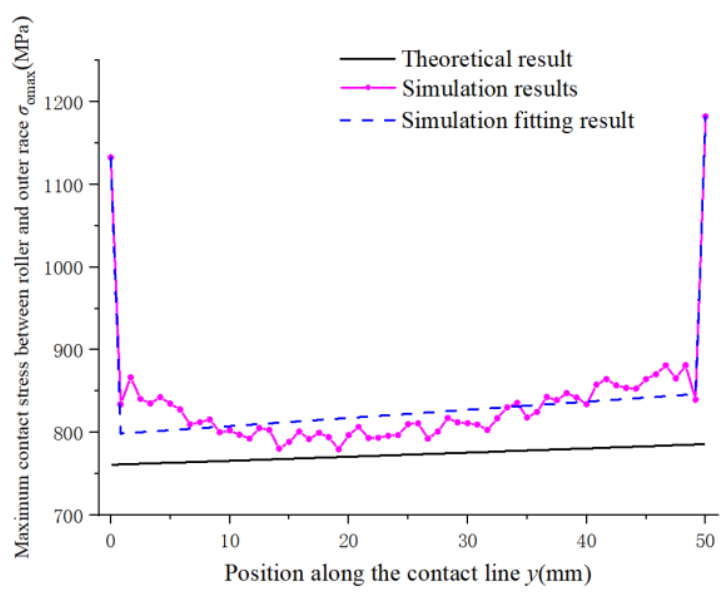

b) Between the roller and the outer raceway

Figure 12: Distribution of maximum contact stress along the contact line.

In the simulation results, the stress distribution fields of the contact areas between the roller and the inner and outer raceways are made by the contact stress values of all the nodes in the contact areas as shown in Fig. 13.

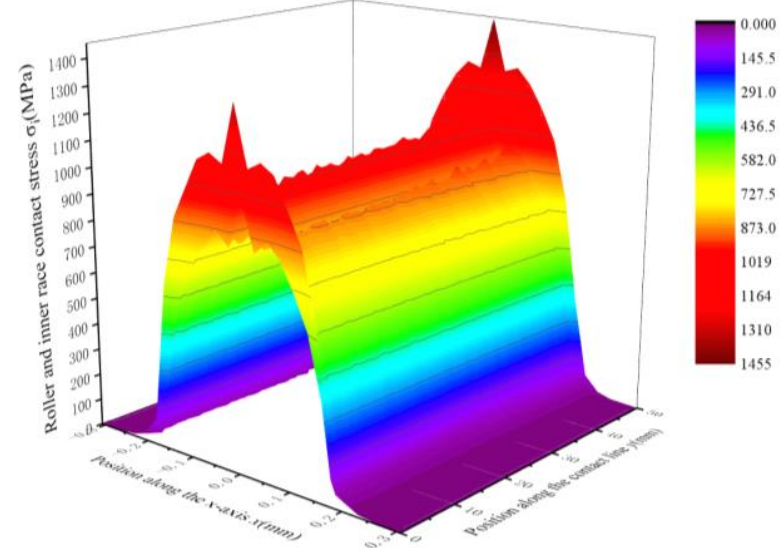

a) Between roller and inner raceway

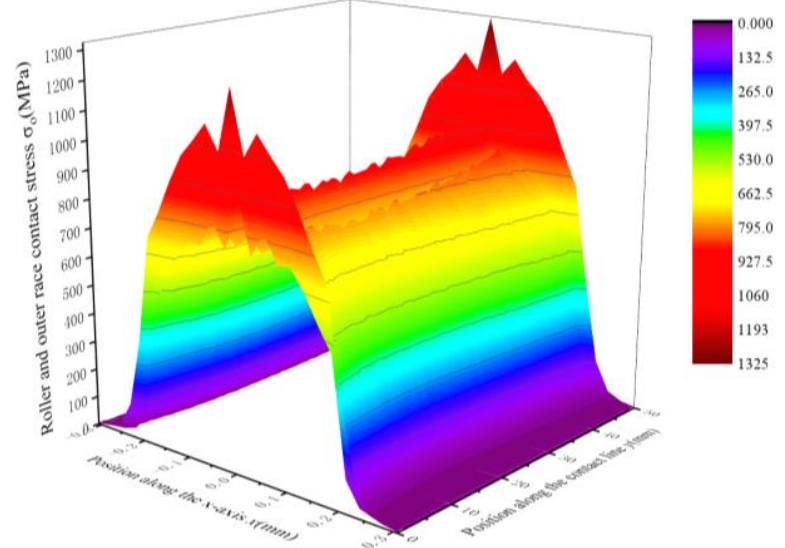

b) Between roller and outer raceway

Figure 13: Stress field in contact area.

\section{DISCUSSION AND CONCLUSION}

In order to more effectively ensure the safe operation of the EMU and reveal the load distribution and internal contact state of the axle box bearing, the static analysis model and 
FES model of the double-row tapered roller bearing were established. The analysis was carried out using the measured load data, and the simulated contact stress was compared with the results calculated based on the Hertz theory. The following conclusions were drawn from the research:

(1) The load distribution of double-row tapered roller bearings is analysed by the static model using the measured load data. The results show that the load in the double-row tapered roller bearing decreases with the increase of the azimuth angle until the roller is not affected by the load outside the bearing zone. In the direction of the axial load, the first row of rollers is subjected to a large contact load, and the second column is subjected to a small contact load. This is due to the special structure of the double-row tapered roller bearing, which causes the bearing to be subjected to both radial and axial loads.

(2) Under normal operating conditions, the maximum contact load of the axle box bearing occurs at an azimuth angle of $0^{\circ}$, and the maximum load is $12.49 \mathrm{kN}$. The contact areas between the bearing and the inner and outer raceways of the bearing are elongated rectangular zones. The contact stress between the roller and the inner raceway is larger than that between the roller and the outer raceway. The maximum contact stress is approximately 1,000 MPa.

(3) The simulation results of the contact stresses between the roller and the inner and outer raceways are consistent with the Hertz theoretical calculation results, all of which have a linear relation. The contact stress of the small end of the roller is large, but the errors of the two are within a reasonable range. The simulation results show the stress concentrations at both ends of the roller, which reflect the edge effect of the bearing roller. In addition, the contact stresses of both raceways are semi-elliptical in the direction of the half width of the contact.

In this study, the load distribution of the double-row tapered roller bearing of the EMU axle box is given, and the roller with the maximum contact load is taken. By comparing the two methods of Hertz theoretical calculation and FES, the distributions of the roller contact stress in the contact areas are obtained and compared. The results can provide guidance for the design of EMU axle box bearings and related theoretical research. However, the research results correspond to the ideal linear roller. The actual tapered roller is convex, which can affect the contact state and characteristics of the bearing to a certain extent, a topic that requires further investigation.

\section{ACKNOWLEDGEMENT}

This study was supported by the National Natural Science Foundation of China (Grant Nos. 71172076, 71302033 and 11872255) and Research Project of Zhejiang Provincial Special Equipment Inspection and Research Institute (Grant No. ZTJ-201901002).

\section{REFERENCES}

[1] Wang, Z.; Zhang, W.; Yin, Z.; Cheng, Y.; Huang, G.; Zou, H. (2019). Effect of vehicle vibration environment of high-speed train on dynamic performance of axle box bearing, Vehicle System Dynamics, Vol. 57, No. 4, 543-563, doi:10.1080/00423114.2018.1473615

[2] Huang, H.; Ma, N.; Hashimoto, T.; Murakawa, H. (2015). Welding deformation and residual stresses in arc welded lap joints by modified iterative analysis, Science and Technology of Welding and Joining, Vol. 20, No. 7, 571-577, doi:10.1179/1362171815Y.0000000040

[3] Liu, J.; Shi, Z.; Shao, Y. (2017). A numerical investigation of the plastic deformation at the spall edge for a roller bearing, Engineering Failure Analysis, Vol. 80, 263-271, doi:10.1016/j.engfailanal.2017.06.019

[4] Zha, H.; Ren, Z.; Xue, R.; Xu, N. (2018). Study on cumulative damage and fatigue life of axle box bearings in high-speed EMU, Journal of the China Railway Society, Vol. 40, No. 10, 30-35, doi:10.3969/j.issn.1001-8360.2018.10.005 
[5] Morales Espejel, G. E.; Gabelli, A. (2016). A model for rolling bearing life with surface and subsurface survival: sporadic surface damage from deterministic indentations, Tribology International, Vol. 96, 279-288, doi:10.1016/j.triboint.2015.12.036

[6] Tong, V.-C.; Hong, S.-W. (2016). Fatigue life of tapered roller bearing subject to angular misalignment, Proceedings of the Institution of Mechanical Engineers, Part C: Journal of Mechanical Engineering Science, Vol. 230, No. 2, 147-158, doi:10.1177/0954406215578706

[7] Tong, V.-C.; Hong, S.-W. (2017). Study on the stiffness and fatigue life of tapered roller bearings with roller diameter error, Proceedings of the Institution of Mechanical Engineers, Part J: Journal of Engineering Tribology, Vol. 231, No. 2, 176-188, doi:10.1177/1350650116649889

[8] Houpert, L. (2015). Load-displacement relationships for ball and spherical roller bearings, Journal of Tribology, Vol. 137, No. 2, Paper 021102, doi:10.1115/1.4029042

[9] Wei, Y.; Wang, F.; Li, H.; Liu, Y. (2014). Load distribution and dynamic simulation of tapered roller bearing, Journal of Dalian Jiaotong University, Vol. 35, No. z1, 60-63, doi:10.13291/j.cnki.djdxac.2014.s1.014

[10] Yan, J.; Zhu, L.; Zhao, S.; Song, S.; Wang, F. (2012). Analysis on load distribution of high-speed railway axle box bearings, Bearing, No. 10, 12-16, doi:10.19533/j.issn1000-3762.2012.10.003

[11] Slack, T.; Sadeghi, F. (2010). Explicit finite element modeling of subsurface initiated spalling in rolling contacts, Tribology International, Vol. 43, No. 9, 1693-1702, doi:10.1016/ j.triboint.2010.03.019

[12] Zamponi, L.; Mermoz, E.; Linares, J. M.; Sprauel, J. M. (2009). Impact of geometrical defects on bearing assemblies with integrated raceways in aeronautical gearboxes, Mechanism and Machine Theory, Vol. 44, No. 6, 1108-1120, doi:10.1016/j.mechmachtheory.2008.10.005

[13] Yin, B.; Xia, X.; Gao, L. (2012). Finite element analysis on dynamic characteristics of deep groove ball bearings with point defects, Bearing, No. 6, 25-30, doi:10.19533/j.issn1000$\underline{3762.2012 .06 .010}$

[14] Cui, J.; Zhang, L. L.; Tian, Y. F.; Zhang, X. Y. (2013). Establishment and application of an equivalent impact model of coupler in front of subway locomotive, Applied Mechanics and Materials, Vol. 251, 36-41, doi:10.4028/www.scientific.net/amm.251.36

[15] Wang, L.-Q.; Cui, L.; Zheng, D.-Z.; Gu, L. (2009). Nonlinear dynamic behaviors of ball bearing rotor system, Journal of Harbin Institute of Technology, Vol. 16, No. 2, 284-288, doi:10.11916/j.issn.1005-9113.2009.02.028

[16] Bagheri, M.; Khoshnoudian, F. (2014). The effect of impact with adjacent structure on seismic behavior of base-isolated buildings with DCFP bearings, Structural Engineering and Mechanics, Vol. 51, No. 2, 277-297, doi:10.12989/sem.2014.51.2.277

[17] Harris, T. A.; Kotzalas, M. N. (2006). Essential Concepts of Bearings Technology, $5^{\text {th }}$ ed., CRC Press, Boca Raton, 134-156 (Ch. 7)

[18] Liu, D.; Li, Q.; Hu, W.; Pan, W. (2017). Fatigue life prediction of the axle box bearings for highspeed trains, DYNA, Vol. 92, No. 5, 538-544, doi:10.6036/8414 